\title{
Effect of Mountain Convexity on the Locally Strong "Karakkaze" Wind
}

\author{
Akifumi NISHI \\ Graduate School of Life and Environmental Sciences, University of Tsukuba, Tsukuba, Japan \\ and \\ Hiroyuki KUSAKA \\ Center for Computational Science, University of Tsukuba, Tsukuba, Japan \\ (Manuscript received 6 October 2018, in final form 1 April 2019)
}

\begin{abstract}
This study numerically examined how the locally strong "Karakkaze" wind in the Kanto Plain of Japan is affected by terrain shape, particularly by a convex feature in the mountain range. Our method involved running idealized numerical simulations using the Weather Research and Forecast model with a horizontal grid spacing of $3 \mathrm{~km}$. The results revealed that a strong-wind region formed in the lee area of the convex feature, hereafter the semi-basin, and leeward of the semi-basin. In contrast, weak-wind areas formed adjacent to the strong-wind region. These results were consistent with the basic features of the observed surface wind pattern of the Karakkaze during the winter monsoon. However, such a flow pattern did not appear in the numerical simulation with a mountain range that lacked a convex feature.

Sensitivity experiments were also conducted to evaluate the detailed effects of a mountain range with convexity. Sensitivity experiments with different convex shapes revealed that strong winds appeared within and leeward of the semi-basin when the aspect ratio of convexity (ratio of the wave amplitude to the wavelength of the convexity) exceeded about 0.5 . Sensitivity experiments on terrain shape suggested that saddles in the mountain range were not essential to the formation of the Karakkaze, but they could affect its strength. Sensitivity experiments on the mountain Froude number, $\mathrm{Fr}_{m}$, showed that locally strong winds within and leeward of the semi-basin appeared only when the $F_{m}$ was in the range $0.42-1.04$. Sensitivity experiments with surface heat fluxes (SHFs) showed that the basic structure of the strong-wind region in the leeward plain of the convex feature did not depend strongly on SHFs. However, the addition of SHFs reduced the surface wind speed, but increased the size of the strong-wind region.
\end{abstract}

Keywords downslope windstorm; local winds; numerical simulation; mountain effect

Citation Nishi, A., and H. Kusaka, 2019: Effect of mountain convexity on the locally strong "Karakkaze" wind. $J$. Meteor. Soc. Japan, 97, 787-803, doi:10.2151/jmsj.2019-044.

Corresponding author: Hiroyuki Kusaka, Center for Computational Science, University of Tsukuba, 1-1-1, Tennodai, Tsukuba city, Ibaraki 305-8577, Japan

E-mail: kusaka@ccs.tsukuba.ac.jp

J-stage Advance Published Date: 19 April 2019

\section{Introduction}

The flow of an airstream over a mountain can create a strong downslope wind in the lee of the mountain called a "downslope windstorm". The types of topography that promote strong downslope windstorms include a long, high mountain range lying orthogonal to the upwind airstream and a high, isolated mountain 
(e.g., Yoshino 1986; Whiteman 2000). The strength of downslope windstorms is sensitive to the dimensionless mountain Froude number, $F r_{m}$, which is the ratio of the mean wind speed $U$ to the product of the Brunt-Vaisala frequency $N$ and the height of the mountain range $H$. If the height of the mountain range is sufficiently high and $F r_{m}$ is no more than 1.18, the resulting atmospheric mountain waves tend to break and develop a stagnant region over the leeward slope of the mountain range. Below this stagnant area, the downslope windstorm intensifies (e.g., Lilly and Klemp 1979; Smith 1985; Lin and Wang 1996). Such breaking of mountain waves and the associated intense downslope windstorms tend to occur more easily when the leeward slope is steep (Raymond 1972; Lilly and Klemp 1979; Pitts and Lyons 1989; Miller and Durran 1991). Moreover, if the mountain range has a col (saddle), downslope windstorms tend to expand in the region leeward of the col (Saito 1992, 1993). Indeed, such terrain features occur near areas where strong downslope windstorms generate intense winds such as the Chinook (Cook and Topil 1952; Oard 1993), south foehn (Brinkmann 1971; Seibert 1990; Jaubert and Stein 2003; Miltenberger et al. 2016), and Bora (Klemp and Durran 1987; Smith 1987; Gohm et al. 2008; Grisogono and Belušić 2009). The foehn to the east of the Antarctic Peninsula has also been investigated recently (e.g., Elvidge and Renfrew 2016; King et al. 2017).

In Japan, strong, local winds blow in several areas (Kusaka and Fudeyasu 2017). For example, the "Yamajikaze" (Saito and Ikawa 1991; Saito 1993) and the "Hirodokaze" (Fudeyasu et al. 2008) are locally famous, strong downslope windstorms. The "Karakkaze", wind in the Kanto region, is also a well-known, strong local wind in Japan (Fig. 1a). The Karakkaze blows when the winter monsoon is strong. During a Karakkaze event, high pressure lies to the west of Japan, and low pressure lies to the east (Yoshino 1986; Kusaka et al. 2011). The strong-wind region of the Karakkaze has a remarkable, fan-shaped, horizontal distribution (Fig. 1a) and expands outward in the lee of a valley about $60 \mathrm{~km}$ wide (Yoshino 1986). The mountain range at the northwest edge of the Kanto Plain is convex on the windward side and concave on the leeward side. The "Tokachi-Kaze", which is the local wind in the Tokachi Plain of Hokkaido, also has a wind pattern similar to the Karakkaze (Fig. $1 \mathrm{~b}$ ), and a portion of the terrain in the area where the Tokachi-Kaze blows is also convex. According to Whiteman (2000), the shape of the mountain range affects the speed of the winds associated with leeward mountain waves. Nishi and Kusaka (2019) revealed that mechanisms of strong wind blowing in the lee of convexity and gap differ, although their spatial patterns of surface wind are similar to each other. However, they did not examine the impact of convexity shapes (e.g., the width of exit and the amplitude of convexity) on the winds. The impact of convexity shapes is important for clarifying whether similar strong winds could blow in other regions. In addition, they did not investigate the effects of the SHFs on the convexity winds. Therefore, there are still a lot of uncertainties about the effect of convexity on leeward winds.

The principal goal of this study is, therefore, to clarify the effects on the Karakkaze of the convex section of the mountains along the northwest edge of the Kanto Plain. Such idealized simulations have been successfully used to simulate downslope winds elsewhere (e.g., Lin and Wang 1996; Epifanio and Durran 2001; Gabersek and Durran 2004). We also evaluated the sensitivity to $F_{m}$ of the strong winds within and leeward of the semi-basin, such as the Karakkaze. Moreover, we examined the sensitivity of these same winds to the impact of the convexity shapes to clarify whether similar strong winds could blow in other regions (e.g., the Tokachi-Kaze). Finally, we investigated how surface heat fluxes (SHFs) affected the region of strong winds in the plain leeward of the convexity.

\section{Simulation method}

For the simulation, we used the advanced research version of the weather research and forecasting (WRF) model (Skamarock et al. 2008). The simulation domain consisted of $210(\mathrm{X}) \times 190(\mathrm{Y})$ grid points with a horizontal grid spacing of $3 \mathrm{~km}$. The domain was $20 \mathrm{~km}$ high and the vertical dimension was simulated with 50 sigma levels. We used a damping layer near the top of the domain to prevent the reflection of gravity waves from the boundary at the top of the domain (Klemp and Lilly 1987). We used open boundary conditions at the lateral boundaries. These boundary conditions have been used widely in idealized numerical simulations of mountain waves with the WRF.

For the topography, we used a simplified shape designed to approximate the $60-\mathrm{km}$-wide valley in the northwest part of the area where the Karakkaze blows (Fig. 1a). Figure 2a shows the terrain used in the simulation. This shape was calculated as follows: 
(a) 2002/02/19 1200 LST

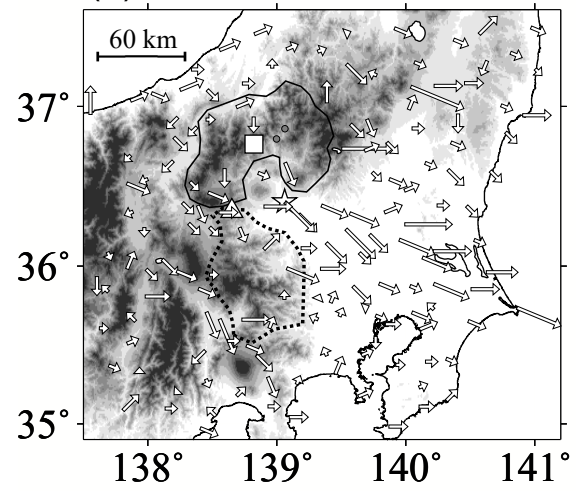

(b) 2011/05/02 1600 LST

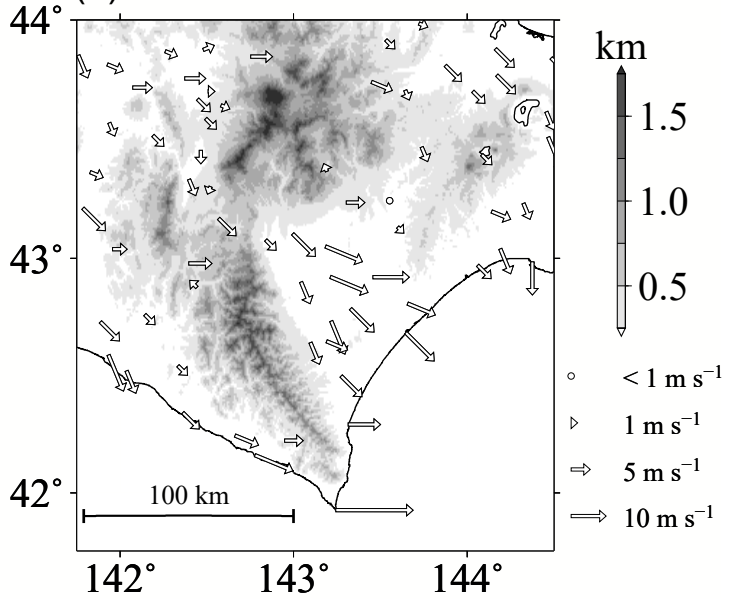

Fig. 1. Surface wind distribution of typical cases of (a) the Karakkaze (1200 LST on 19 February 2002), (b) the Tokachi-Kaze (1600 LST on 2 May 2011). Data from the automated meteorological data acquisition system. The shading shows terrain height. The star, triangle, and square in (a) show the location of Maebashi, Usui saddle, and Mikuni saddle, respectively. The black and dotted black lines show the Mikuni and Kanto mountains, respectively.

(a)

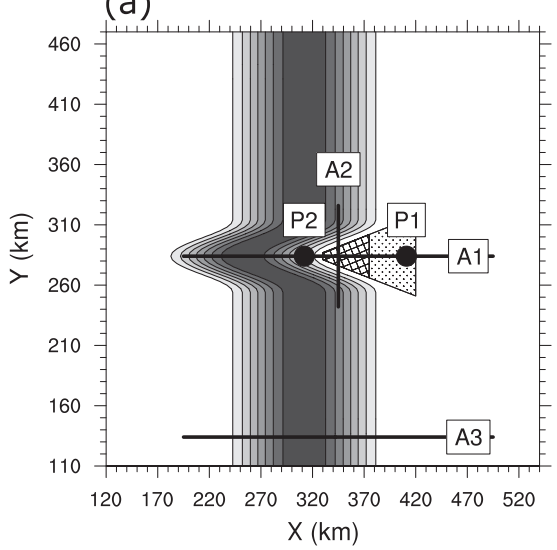

(b)

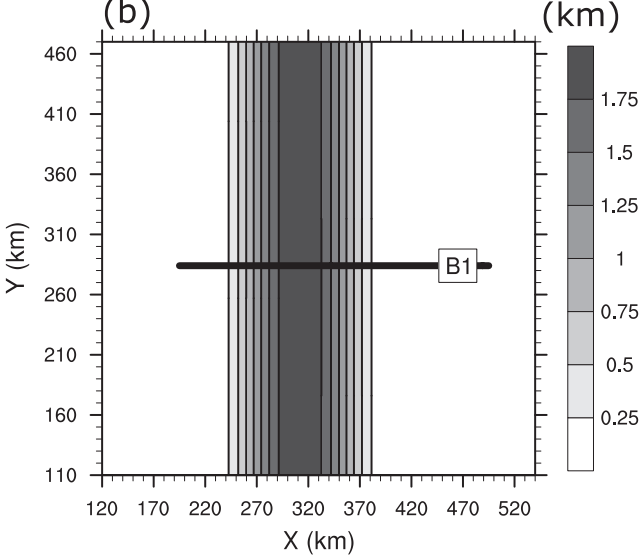

Fig. 2. Topography for the numerical simulations, (a) Topography expressed by Eq. (1). The contour intervals are $0.25 \mathrm{~km}$. Lines A1, A2, and A3 are cross section locations for Figs. 4 and 5. Points P1 and P2 are the locations for Figs. 9 and 10. The cross-hatched area is the "semi-basin area (b) Same as (a) except for the Straight-SHF case. Line segment B1 is the location of the cross section for Fig. 11.

$$
\operatorname{MNT}(x, y)= \begin{cases}\frac{H}{2}\left(1-\cos \left(\frac{2 \pi(x-a)}{L_{W}}\right)\right) & a \leq x \leq a+L_{W} \\ 0 & \text { otherwise. }\end{cases}
$$

where

$$
a= \begin{cases}X_{c}-\frac{L_{W}}{2}-A_{b} \sin \left(\frac{\pi}{L_{b}}\left(y+L_{b}-Y_{c}\right)\right)^{2}, & Y_{c}-\frac{L_{b}}{2} \leq y \leq Y_{c}+\frac{L_{b}}{2} ; \\ X_{c}-\frac{L_{W}}{2}, & \text { otherwise. }\end{cases}
$$


Table 1. Physical parameterization schemes and parameters used in the simulations.

\begin{tabular}{|c|c|c|}
\hline Variable & Without SHFs & With SHFs \\
\hline Shortwave radiation & Not included & Dudhia simple scheme (Dudhia 1989) \\
\hline Longwave radiation & Not included & $\begin{array}{c}\text { Rapid Radiative Transfer Model } \\
\text { (Mlawer et al. 1997) }\end{array}$ \\
\hline Planetary boundary layer & \multicolumn{2}{|c|}{$\begin{array}{l}\text { Mellor-Yamada-Nakanishi-Niino scheme } \\
\text { (Mellor and Yamada 1982; Nakanishi and Niino 2009) }\end{array}$} \\
\hline Land surface heat budget & $\begin{array}{l}\text { Noah land surface model (Chen and } \\
\text { Dudhia 2001) without SHFs }\end{array}$ & Noah land surface model \\
\hline Roughness length & \multicolumn{2}{|c|}{$0.1 \mathrm{~m}$} \\
\hline Reference latitude and longitude & \multicolumn{2}{|c|}{$36^{\circ} \mathrm{N}, 140^{\circ} \mathrm{E}$} \\
\hline Reference date & \multicolumn{2}{|c|}{19 December 2002} \\
\hline
\end{tabular}

In Eq. (1), the ridge height $(H)$ and width $\left(L_{W}\right)$ were $2 \mathrm{~km}$ and $180 \mathrm{~km}$, respectively. The center of the domain in the horizontal plane $\left(X_{c}, Y_{c}\right)$ was at (315 $\mathrm{km}, 282.5 \mathrm{~km})$. The parameters $A_{b}$ and $L_{b}$ were the amplitude and wavelength of the convex section. To approximate the Karakkaze region, we assumed that both $A_{b}$ and $L_{b}$ equaled $60 \mathrm{~km}$. We called the flat area surrounded by slopes on three sides, just lee of the convex region, the "semi-basin" (cross-hatched area in Fig. 2a).

During a Karakkaze, the observed average wind speed from 925 to $850 \mathrm{hPa}$ is usually about $10 \mathrm{~m} \mathrm{~s}^{-1}$, and the potential temperature lapse rate is about 4.0 $\times 10^{-3} \mathrm{~K} \mathrm{~m}^{-1}$. Therefore, we used the following atmospheric profile for the initial conditions for all grids. The wind speed was $10 \mathrm{~m} \mathrm{~s}^{-1}$, and the wind blew from the west. Both conditions were independent of height. The vertical gradient of the potential temperature was $4.0 \times 10^{-3} \mathrm{~K} \mathrm{~m}^{-1}$, and the potential temperature at sea level was $280 \mathrm{~K}$. These conditions gave an $F r_{m}$ of 0.42 . The numerical simulation was then run for 24 hours. In the Convexity-SHF case (vide infra), the simulation started at 0600 local standard time (LST). Table 1 shows the longitude, latitude, and reference date. In the Convexity-SHF case, the flow was analyzed at 6 forecast times (FTs), each of which corresponded to 1200 LST. In the Convexity-noSHF case, the flow at 21 FTs was analyzed.

The sensitivity of the results to the initial conditions was examined to understand the influence of atmospheric conditions in the windward region of the mountain range (i.e., $F r_{m}$ ) on the strength of the wind in the lee of the convex region of the mountain range. In the sensitivity experiments, we used eight values of $F r_{m}(0.21,0.42,0.63,0.83,1.04,1.25 .1 .48$, and 1.67), including the control value of $F r_{m}(0.42)$ (Tables 2, 3,
$5)$.

To clarify the impact of the degree of convexity, sensitivity experiments were conducted with various scales of convexity by varying $A_{b}$ and $L_{b}$ in Eq. (1). Specifically, $A_{b}$ and $L_{b}$ values of $30,60,90,120,150$, or $180 \mathrm{~km}$ were assigned and 36 experiments were conducted with all possible combinations of $A_{b}$ and $L_{b}$. Those experiments included a control experiment with $A_{b}$ and $L_{b}$ each assigned a value of $60 \mathrm{~km}$; this assignment is appropriate for the semi-basin in the Kanto region where the Karakkaze occurs. All experiments were conducted both with and without SHFs (Tables $2,4,6)$. Surface friction was considered in all these experiments, regardless of the presence of SHFs.

To better understand the importance of convexity, we also ran a "Straight-SHF case" simulation with just a simple, straight ridge (Fig. 2b, Table 2) but with all other settings the same as those used in the ConvexitySHF case.

The Coriolis force plays an important role in the formation of the two-layer flow pattern of the "shallow foehn" in the Alps (Sprenger and Schär 2001; Zäng1 et al. 2004). However, we ignored the Coriolis force in our idealized simulations to facilitate understanding of the results. Because a typical Rossby number $(R o=$ $U / f L$ with $U=10 \mathrm{~m} \mathrm{~s}^{-1}, f=8.0 \times 10^{-5} \mathrm{~s}^{-1}$, and $L=60$ $\mathrm{km}$ ) during a Karakkaze event is about 2, this simplification should give qualitatively reasonable results. In a preliminary simulation, the above configuration was confirmed to be adaptable by comparing the results of the simulation with and without the Coriolis force (see Supplement 1).

Table 1 summarizes the physical parameterization schemes and the parameters used in the simulations. To examine the dynamical processes associated with a strong wind in the leeward plain of the semi-basin, the 
Table 2. Summaries of the experiments.

\begin{tabular}{|c|c|c|c|}
\hline Case name & Terrain shape & $\begin{array}{c}\text { Surface } \\
\text { heat fluxes }\end{array}$ & $\begin{array}{l}\text { Mountain Froude number } \\
\qquad\left(F r_{m}\right)\end{array}$ \\
\hline Convexity-noSHF case & \multirow{4}{*}{$\begin{array}{l}\text { Figure } 2 \mathrm{a} \\
\text { The length scales of convexity } \\
\left(A_{b} \text { and } L_{b}\right) \text { were } 60 \mathrm{~km} \text { (see text). }\end{array}$} & Off & 0.42 \\
\hline Convexity-SHF case & & On & 0.42 \\
\hline Convexity-noSHF-F $\left[F_{m}\right]$ case & & Off & \multirow{2}{*}{$\begin{array}{l}0.21,0.63,0.83,1.04,1.25 \\
1.48 \text {, and } 1.67 \text { in both cases }\end{array}$} \\
\hline Convexity-SHF-F $\left[F r_{m}\right]$ case & & On & \\
\hline Convexity-noSHF-A $\left[A_{b}\right]-\mathrm{L}\left[L_{b}\right]$ case & \multirow{2}{*}{$\begin{array}{l}\text { Like Fig. } 2 a \text {, except that the length } \\
\text { scales of convexity are different. } \\
{\left[A_{b}\right] \text { and }\left[L_{b}\right] \text { are the length scales }} \\
\text { of convexity (units are km). }\end{array}$} & Off & 0.42 \\
\hline Convexity-SHF- $\mathrm{A}\left[A_{b}\right]-\mathrm{L}\left[L_{b}\right]$ case & & On & 0.42 \\
\hline Straight-SHF case & Figure $2 b$ & On & 0.42 \\
\hline Convexity-Saddle-SHF case & Figure $12 \mathrm{a}$ & On & 0.42 \\
\hline
\end{tabular}

Table 3. Impact of mountain Froude number $\left(F r_{m}\right)$ on the hydraulic jump and surface winds at $21 \mathrm{FT}$ for the Convexity-noSHF-F $\left[F r_{m}\right]$ cases.

\begin{tabular}{|c|c|c|c|c|c|}
\hline \multirow{3}{*}{$F r_{m}$} & \multirow{3}{*}{ Wind speed } & \multicolumn{4}{|c|}{ Cross section A1 } \\
\hline & & \multicolumn{2}{|c|}{ Maximum updraft at height of $2000 \mathrm{~m}$} & \multirow{2}{*}{$\begin{array}{l}\text { Hydraulic jump } \\
\text { over the leeward } \\
\text { mountain slope }\end{array}$} & \multirow{2}{*}{$\begin{array}{l}\text { Surface maximum } \\
\text { westerly wind speed } \\
\text { at leeward plain }\end{array}$} \\
\hline & & The intense & The position & & \\
\hline unit & {$\left[\mathrm{m} \mathrm{s}^{-1}\right]$} & {$\left[\mathrm{m} \mathrm{s}^{-1}\right]$} & {$[\mathrm{km}]$} & & {$\left[\mathrm{m} \mathrm{s}^{-1}\right]$} \\
\hline 0.21 & 5 & 0.8 & 303 & X (absence) & 0.1 \\
\hline \multicolumn{2}{|c|}{ (The Convexity-noSHF case) } & 1.0 & 318 & $\mathrm{X}$ & 11.4 \\
\hline 0.63 & 15 & 1.3 & 330 & $\mathrm{X}$ & 17.8 \\
\hline 0.83 & 20 & 1.3 & 333 & $\mathrm{X}$ & 21.4 \\
\hline 1.04 & 25 & 2.9 & 360 & $\mathrm{X}$ & 29.9 \\
\hline 1.25 & 30 & 3.4 & 375 & $\mathrm{X}$ & 15.5 \\
\hline 1.48 & 35 & 3.5 & 387 & $\mathrm{X}$ & 10.9 \\
\hline \multirow[t]{2}{*}{1.67} & 40 & 3.1 & 399 & $\mathrm{X}$ & 10.6 \\
\hline & & \multicolumn{4}{|c|}{ Cross section A3 } \\
\hline 0.21 & 5 & 0.4 & 357 & $\mathrm{O}$ (presence) & 0.1 \\
\hline \multicolumn{2}{|c|}{ (The Convexity-noSHF case) } & 1.7 & 354 & O & -0.5 \\
\hline 0.63 & 15 & 3.1 & 357 & $\mathrm{O}$ & 0.9 \\
\hline 0.83 & 20 & 3.0 & 357 & $\mathrm{O}$ & 5.8 \\
\hline 1.04 & 25 & 9.5 & 366 & $\mathrm{O}$ & 8.6 \\
\hline 1.25 & 30 & 11.4 & 375 & $\mathrm{X}$ & 8.8 \\
\hline 1.48 & 35 & 11.6 & 405 & $\mathrm{X}$ & 8.0 \\
\hline 1.67 & 40 & 12.0 & 453 & $\mathrm{X}$ & 8.7 \\
\hline
\end{tabular}

simulation was first run without shortwave radiation, longwave radiation, and SHFs. This simulation was "the Convexity-noSHF case". Note that Nishi and Kusaka (2019) conducted the same simulation as the Convexity-noSHF case. However, Nishi and Kusaka (2019) did not show the detail structures of wind and potential temperature for the Convexity-noSHF case; thus, the present study shows more detail structure of the three-dimensional wind and potential temperature structures (e.g., in the semi-basin). To examine the impacts of surface heating and cooling on the same system, we then included shortwave radiation, longwave radiation, and SHFs in the simulation (Table 2). This simulation was the "Convexity-SHF case". To facilitate the interpretation of the results, we did not use a cloud microphysics scheme. 
Table 4. Impact of the shape of the convex region on the formation of locally strong winds at 21 FT in the semi-basin without SHFs (The Convexity-noSHF-A $\left[A_{b}\right]-\mathrm{L}\left[L_{b}\right]$ cases). The values are the surface wind speeds in the leeward plain of cross Sections A1 and A3. The bold text means the presence of a locally strong wind. A strong wind means that the maximum surface wind speed exceeded $8.0 \mathrm{~m} \mathrm{~s}^{-1}$.

\begin{tabular}{|c|c|c|c|c|c|c|c|c|c|c|c|c|c|}
\hline & & \multicolumn{12}{|c|}{$L_{b}(\mathrm{~km})$} \\
\hline \multicolumn{2}{|c|}{ Unit: $\mathrm{m} \mathrm{s}^{-1}$} & \multicolumn{2}{|c|}{30} & \multicolumn{2}{|c|}{60} & \multicolumn{2}{|c|}{90} & \multicolumn{2}{|c|}{120} & \multicolumn{2}{|c|}{150} & \multicolumn{2}{|c|}{180} \\
\hline Cross & ection & A1 & A3 & A1 & A3 & A1 & A3 & A1 & A3 & A1 & A3 & A1 & A3 \\
\hline \multirow{6}{*}{$\begin{array}{c}A_{b} \\
(\mathrm{~km})\end{array}$} & 30 & 10.3 & -0.7 & 7.9 & -0.8 & 6.2 & -0.8 & 5.4 & -0.9 & 4.9 & -0.8 & 4.3 & -0.8 \\
\hline & 60 & 12.1 & -0.8 & 11.4 & -0.5 & 9.6 & -0.8 & 9.5 & -0.8 & 8.0 & -0.8 & 6.4 & -0.8 \\
\hline & 90 & 12.6 & -0.8 & 12.9 & -0.8 & 11.6 & -0.2 & 9.7 & -0.4 & 10.0 & -0.4 & 9.2 & -0.6 \\
\hline & 120 & 13.9 & -0.8 & 10.4 & -0.9 & 12.1 & -0.4 & 10.4 & -0.1 & 9.7 & -0.1 & 9.6 & -0.1 \\
\hline & 150 & 12.5 & -0.7 & 11.6 & -0.9 & 10.4 & -0.7 & 12.5 & -0.2 & 10.4 & -0.1 & 9.9 & -0.1 \\
\hline & 180 & 12.5 & -0.7 & 11.5 & -0.8 & 9.0 & -0.7 & 11.0 & -0.3 & 11.1 & -0.3 & 10.2 & -0.1 \\
\hline
\end{tabular}

Table 5. Same as Table 3, except for the Convexity-SHF-F $\left[F_{m}\right]$ cases at 6 FT.

\begin{tabular}{|c|c|c|c|c|c|}
\hline \multirow{3}{*}{$F r_{m}$} & \multirow{3}{*}{ Wind speed } & \multicolumn{4}{|c|}{ Cross section A1 } \\
\hline & & \multicolumn{2}{|c|}{ Maximum updraft at height of $2000 \mathrm{~m}$} & \multirow{2}{*}{$\begin{array}{l}\text { Hydraulic jump } \\
\text { over the leeward } \\
\text { mountain slope }\end{array}$} & \multirow{2}{*}{$\begin{array}{c}\text { Surface maximum } \\
\text { westerly wind speed } \\
\text { at leeward plain }\end{array}$} \\
\hline & & The intense & The position & & \\
\hline unit & {$\left[\mathrm{m} \mathrm{s}^{-1}\right]$} & {$\left[\mathrm{m} \mathrm{s}^{-1}\right]$} & {$[\mathrm{km}]$} & & {$\left[\mathrm{m} \mathrm{s}^{-1}\right]$} \\
\hline 0.21 & 5 & 0.1 & 321 & $\mathrm{X}$ (absence) & 0.5 \\
\hline \multicolumn{2}{|c|}{ (The Convexity-noSHF case) } & 0.3 & 402 & $\mathrm{X}$ & 9.3 \\
\hline 0.63 & 15 & 0.7 & 381 & $\mathrm{X}$ & 12.4 \\
\hline 0.83 & 20 & 0.6 & 432 & $\mathrm{X}$ & 14.1 \\
\hline 1.04 & 25 & 1.1 & 324 & $\mathrm{X}$ & 23.9 \\
\hline 1.25 & 30 & 0.8 & 318 & $\mathrm{X}$ & 25.9 \\
\hline 1.48 & 35 & 1.7 & 312 & $\mathrm{X}$ & 27.0 \\
\hline \multirow[t]{2}{*}{1.67} & 40 & 1.9 & 324 & $\mathrm{X}$ & 27.4 \\
\hline & & \multicolumn{4}{|c|}{ Cross section A3 } \\
\hline 0.21 & 5 & 0.8 & 345 & $\mathrm{O}$ (presence) & 0.5 \\
\hline \multicolumn{2}{|c|}{ (The Convexity-noSHF case) } & 3.0 & 357 & (4 & 0.8 \\
\hline 0.63 & 15 & 6.1 & 369 & $\mathrm{O}$ & 5.6 \\
\hline 0.83 & 20 & 7.5 & 381 & $\mathrm{O}$ & 8.2 \\
\hline 1.04 & 25 & 8.3 & 393 & $\mathrm{O}$ & 7.9 \\
\hline 1.25 & 30 & 0.8 & 402 & $X$ & 9.4 \\
\hline 1.48 & 35 & 0.5 & 402 & $X$ & 11.5 \\
\hline 1.67 & 40 & 0.3 & 450 & $X$ & 13.4 \\
\hline
\end{tabular}

Table 6. Same as Table 4, except for the Convexity-SHF-A $\left[A_{b}\right]-\mathrm{L}\left[L_{b}\right]$ cases at 6 FT.

\begin{tabular}{|c|c|c|c|c|c|c|c|c|c|c|c|c|c|}
\hline \multirow{2}{*}{\multicolumn{2}{|c|}{ Unit: $\mathrm{m} \mathrm{s}^{-1}$}} & \multicolumn{12}{|c|}{$L_{b}(\mathrm{~km})$} \\
\hline & & \multicolumn{2}{|c|}{30} & \multicolumn{2}{|c|}{60} & \multicolumn{2}{|c|}{90} & \multicolumn{2}{|c|}{120} & \multicolumn{2}{|c|}{150} & \multicolumn{2}{|c|}{180} \\
\hline Cross & ection & A1 & A3 & A1 & A3 & A1 & A3 & A1 & A3 & A1 & A3 & A1 & A3 \\
\hline \multirow{6}{*}{$\begin{array}{c}A_{b} \\
(\mathrm{~km})\end{array}$} & 30 & 9.8 & 1.8 & 9.7 & 1.9 & 9.4 & 1.8 & 8.5 & 1.9 & 7.7 & 2.0 & 4.7 & 2.4 \\
\hline & 60 & 9.4 & 1.8 & 10.4 & 1.7 & 9.0 & 1.9 & 9.6 & 2.0 & 9.5 & 1.8 & 6.7 & 2.3 \\
\hline & 90 & 8.1 & 1.8 & 10.8 & 1.9 & 9.8 & 2.1 & 8.9 & 1.9 & 8.9 & 1.7 & 7.4 & 2.5 \\
\hline & 120 & 9.0 & 1.8 & 12.7 & 1.8 & 10.8 & 1.9 & 10.4 & 1.9 & 10.1 & 2.0 & 8.4 & 2.2 \\
\hline & 150 & 9.4 & 2.2 & 9.5 & 2.3 & 10.4 & 2.7 & 10.4 & 2.8 & 9.7 & 2.5 & 9.0 & 3.2 \\
\hline & 180 & 8.8 & 2.2 & 9.4 & 2.5 & 10.1 & 3.1 & 10.2 & 3.5 & 10.1 & 3.8 & 9.8 & 3.1 \\
\hline
\end{tabular}




\section{Results of the Convexity-noSHF case}

\subsection{Flow pattern around convex mountain range (Convexity-noSHF case)}

We first examined the horizontal distribution of simulated wind speeds at a height of $10 \mathrm{~m}$ using the WRF model without SHFs. In Fig. 3a, a region with wind speeds exceeding $8 \mathrm{~m} \mathrm{~s}^{-1}$, hereafter a 'strongwind region', was apparent at all 21 FTs inside the semi-basin, and it extended leeward into the plain. The highest wind speed occurred at $X=400 \mathrm{~km}$ in the semi-basin area. In contrast, there was a weak westerly wind at the foot of the mountain to the north and south of the semi-basin. Strong winds, therefore, blew locally in the area leeward of the semi-basin. These results agreed with the basic observed features of the Karakkaze; in particular, strong winds blew at Maebashi in the semi-basin (the star in Fig. 1a), and this region of strong winds extended leeward into the Kanto Plain. The local area of wind divergence expanded from inside the semi-basin to the leeward plain of the semi-basin (Figs. 3b-d, $X=345-440$ $\mathrm{km})$. This area of divergent winds was also consistent with observations of the Karakkaze (Fig. 1a), although (a) Windspeed at $Z=10 \mathrm{~m}$

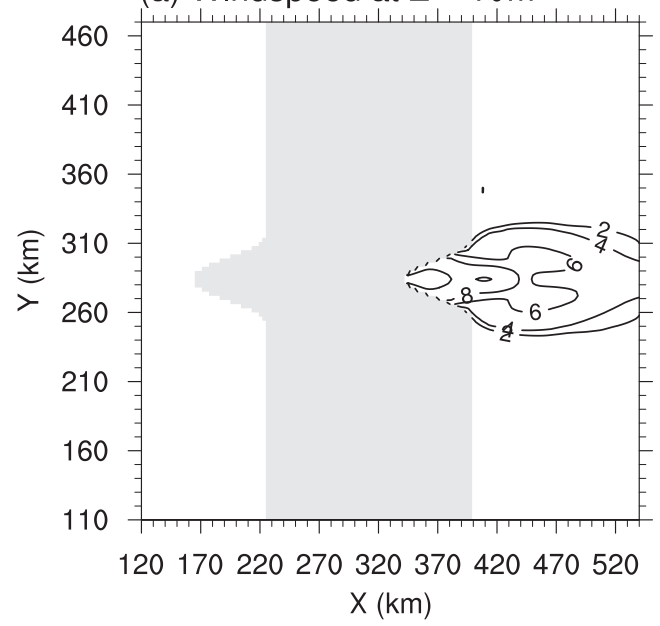

(c) Wind divergence at $Z=10 \mathrm{~m}$

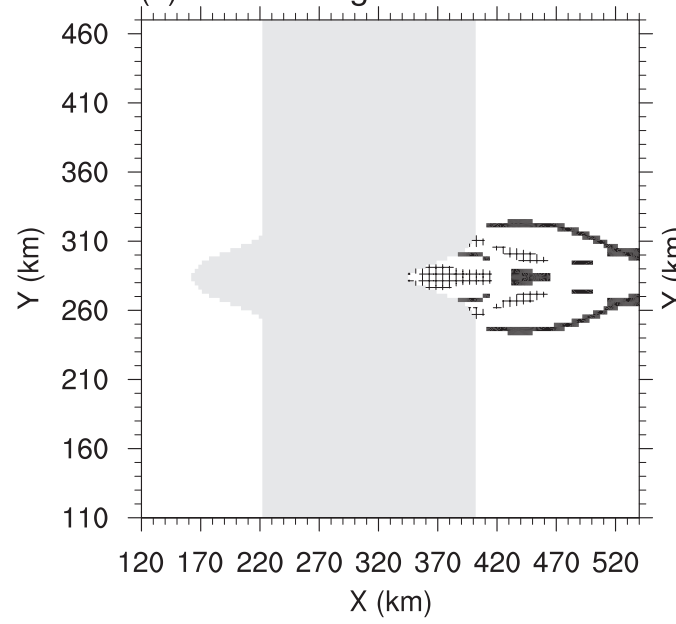

(b) Wind at $Z=10 \mathrm{~m}$

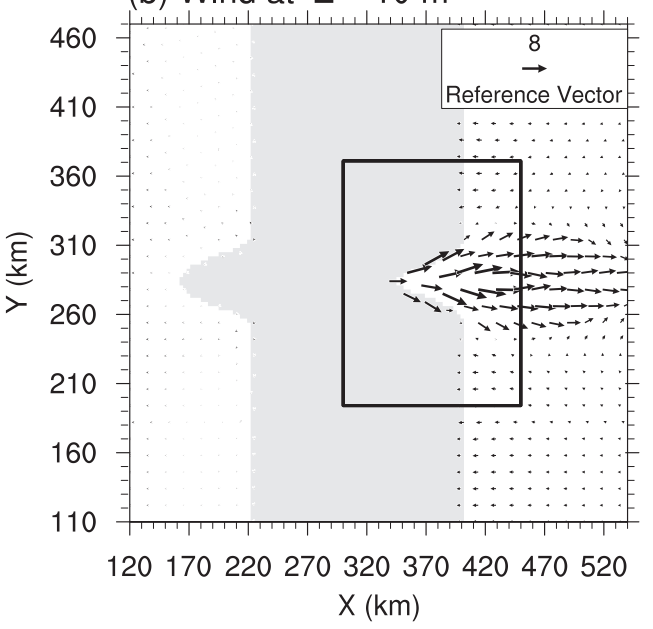

(d) Enlarged view of (b)

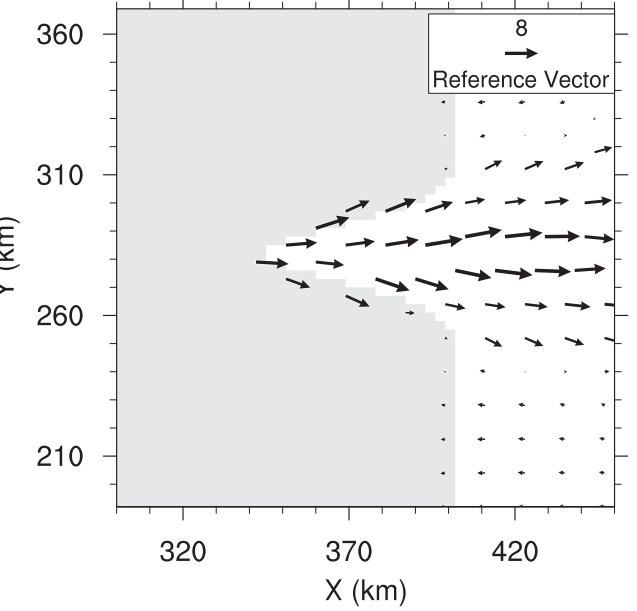

Fig. 3. Horizontal cross section at $\mathrm{z}=10 \mathrm{~m}$ at $21 \mathrm{FT}$ from the Convexity-noSHF case. The area with terrain height above $10 \mathrm{~m}$ is masked out with gray shading. (a) Horizontal wind speed distribution. The contour interval is 2 $\mathrm{m} \mathrm{s}^{-1}$. (b) Horizontal flow patterns. The square is the area of (d). (c) Horizontal wind divergence and convergence. The cross-hatched area means wind divergence exceeds $0.2 \mathrm{~s}^{-1}$, whereas black means the divergence is below strong convergence). (d) An enlarged view of the horizontal flow pattern. These figures are adapted from Nishi and Kusaka (2019). 
the region of strong winds tended to be narrower than the observed region. Moreover, the simulated results also reproduced another important observed feature of the Karakkaze, namely, that strong winds did not blow at the mountain foot north or south of the semi-basin. This idealized simulation, therefore, reproduced the basic features of the horizontal distribution of a Karakkaze.

The contours of wind speed in an $\mathrm{X}-\mathrm{Z}$ cross section located along the center line of the semi-basin (A1 in), and in particular the contour corresponding to 22 $\mathrm{m} \mathrm{s}^{-1}$, descended from an elevation of 4.0 to $0.2 \mathrm{~km}$ (X (a) Windspeed

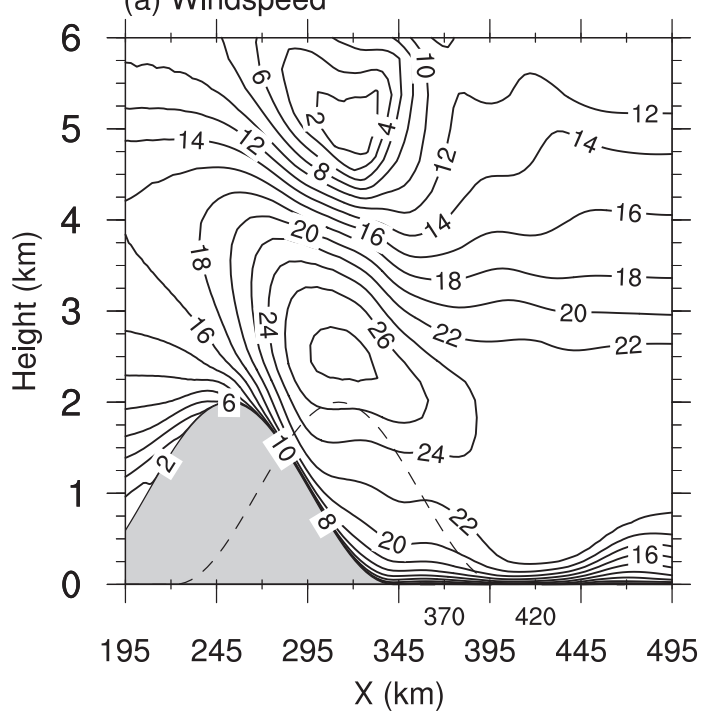

(c) $\mathrm{V}$

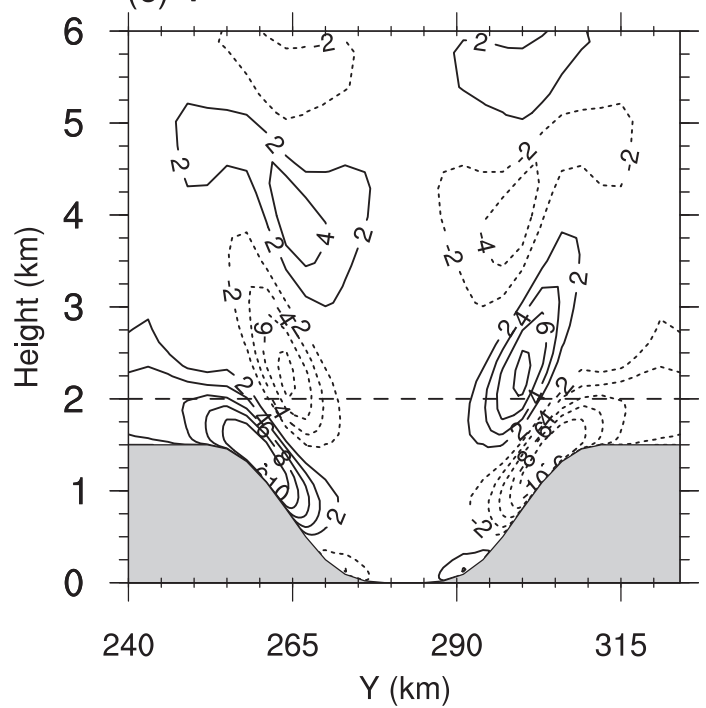

(b) W and $\theta$

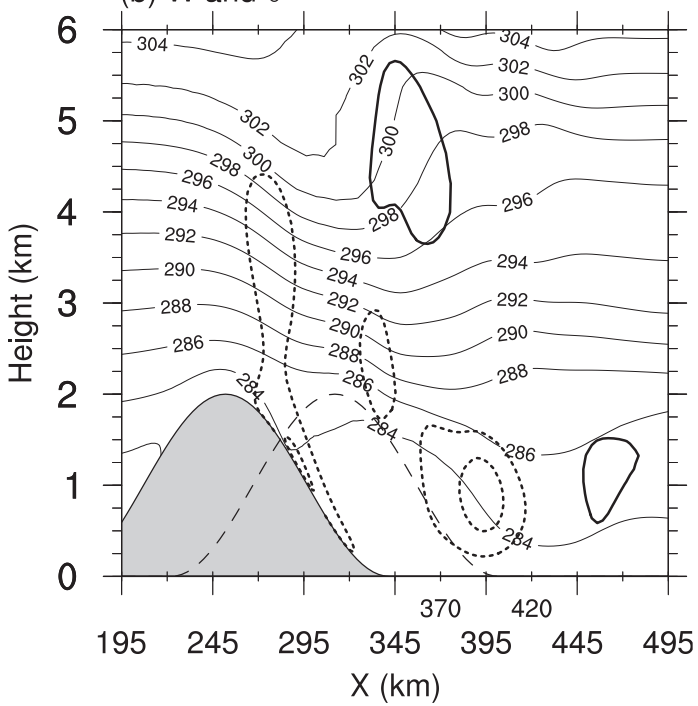

(d) W and $\theta$

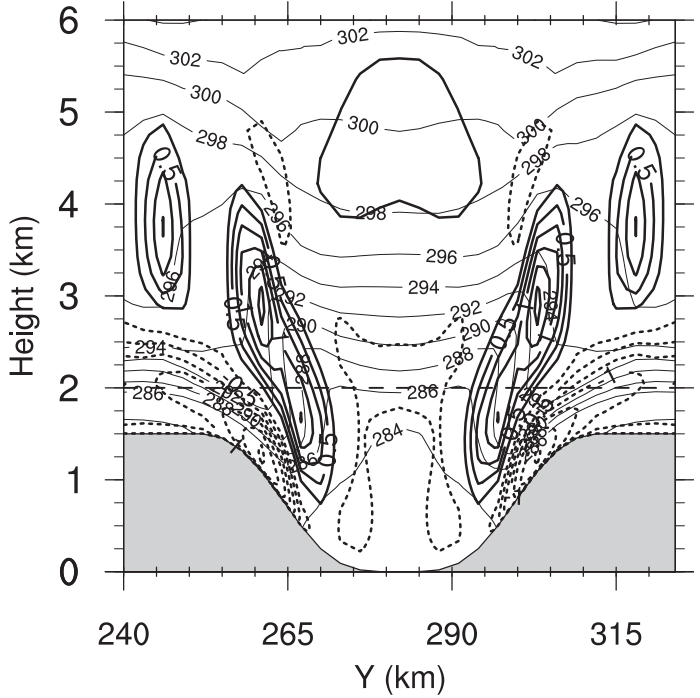

Fig. 4. Wind and potential temperature in vertical cross sections at 21 FT from the Convexity-noSHF case. The shaded area is within the ridge. The dashed line marks the profile of the main ridgeline. (a) Wind speed in $\mathrm{X}-\mathrm{Z}$ cross section along the convexity center-line (A1 in Fig. 2a). The contour interval is $2 \mathrm{~m} \mathrm{~s}^{-1}$. (b) Vertical wind (W, bold lines) and potential temperature $(\theta$, thin lines) in the $\mathrm{X}-\mathrm{Z}$ cross section along $\mathrm{A} 1$. The bold solid lines mark updrafts of $0.25 \mathrm{~m} \mathrm{~s}^{-1}$ or more, the dotted are downdrafts, and the contour intervals are $0.25 \mathrm{~m} \mathrm{~s}^{-1}$. Thin contour intervals are $2 \mathrm{~K}$. (c) Y-component of the winds (V) in Y-Z cross section across the side slopes of the convex feature (A2 in Fig. 2a). Solid lines represent south wind values, dashed represent north. Both contour intervals are $2 \mathrm{~m} \mathrm{~s}^{-1}$. (d) Same as (b) except in the Y-Z cross section along A2. (a) and (b) are adapted from Nishi and Kusaka (2019). 
$=370-420 \mathrm{~km}$ in Fig. 4a). Furthermore, this region had downdrafts that exceeded $0.5 \mathrm{~m} \mathrm{~s}^{-1}$ (Fig. 4b). The location of this descent area $(X=370-420 \mathrm{~km})$ corresponded to a region of high winds (Fig. 3a) and strong divergence (Fig. 3c) at a height of $10 \mathrm{~m}$. This result suggests that the region of strong winds was caused by a downdraft that transported momentum from the westerly wind to the lower layer. In addition, we found that to the north and south of the semi-basin, the wind speed rapidly decreased as the wind descended the mountain toward the leeward plain (Fig. 5a). This behavior was particularly apparent in the region near $X=370 \mathrm{~km}$ in. At this X-position south of the semi-basin, the cross section in Fig. 5b shows the rapid ascent of isentropic lines corresponding to temperatures $\geq 286 \mathrm{~K}$. These results suggest that a hydraulic jump occurred. In contrast, the hydraulic jump did not appear near the surface along the cross Section A1 during the simulation period.

An examination of the Y-component of the wind in the $\mathrm{Y}-\mathrm{Z}$ cross Section A2 in, which is perpendicular to cross Section A1 (Fig. 4c), showed that a southerly wind blew along the southern slope around the semi-basin $(\mathrm{Y}=255-270 \mathrm{~km})$. In contrast to the southern slope, a northerly wind blew along the northern slope of the semi-basin ( $\mathrm{Y}=295-310 \mathrm{~km}$ ). These results indicated that the air flowed into the semi-basin. Moreover, the vertical wind speed in this $\mathrm{Y}-\mathrm{Z}$ cross section (Fig. 4d) showed that downdrafts exceeding
$1.0 \mathrm{~m} \mathrm{~s}^{-1}$ appeared on the southern slope $(\mathrm{Y}=255-270$ $\mathrm{km})$ and the northern slope around the semi-basin (Y $=295-310 \mathrm{~km})$. At the same time $(21 \mathrm{FT})$, updrafts exceeding $1.0 \mathrm{~m} \mathrm{~s}^{-1}$ appeared in the lee of the downdrafts.

These results suggest that a strong-wind region forms in the lee of a convex mountain range due to the following mechanisms: (1) wind convergence and updrafts appear above the semi-basin because of flows that descend over the northern and southern slopes of the semi-basin; (2) at the same time, a relatively strong wind divergence appears near the surface around the leeward plain of the semi-basin; (3) the downdraft transports momentum from the upper air to the ground; and (4) then, a locally strong, divergent wind appears near the ground surface at the leeward plain of the semi-basin.

\subsection{Impact of the mountain Froude number}

Now, we examined the impact of $F r_{m}$ on the strength of the wind in the lee of the convex region of the mountain range (Table 2). The same sensitivity experiments were conducted in Nishi and Kusaka (2019). However, in Nishi and Kusaka (2019), the flow pattern of each experiment was only qualitatively examined by using the sensitivity experiments. Thus, the present study quantitively showed the flow pattern (e.g., maximum wind speed in the leeward plain, the strength of the hydraulic jump, and the position of the (a) Windspeed

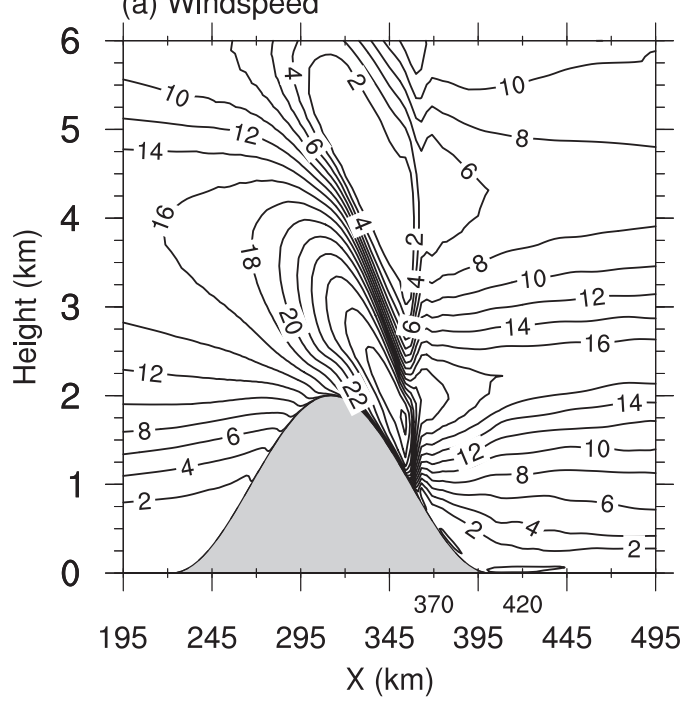

(b) $\theta$

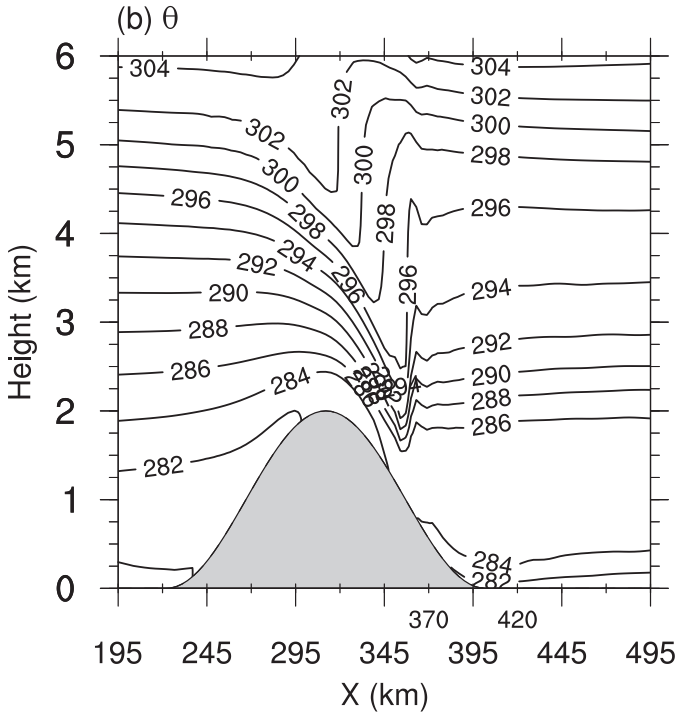

Fig. 5. Wind speed and potential temperature values in the $\mathrm{X}-\mathrm{Z}$ cross section (A3 in Fig. 2a) at $21 \mathrm{FT}$ from the Convexity-noSHF case. (a) Same as Fig. 4a except for a different cross section. (b) Potential temperature $(\theta)$. The contour interval is $2 \mathrm{~K}$. These figures are adapted from Nishi and Kusaka (2019). 
hydraulic jump) in Table 2.

The $F r_{m}$ is an important parameter of the system. We determined how the $F r_{m}$ affected the surface wind by examining the results of eight experiments with various $F r_{m}$ values (Table 3).

The results of the experiments showed that a hydraulic jump played an important role in the formation of the locally strong wind (speed $>8 \mathrm{~m} \mathrm{~s}^{-1}$ ) in the semi-basin. In the Convexity-noSHF-F0.21 case, a hydraulic jump appeared $(X=303 \mathrm{~km})$ along the entire leeward slope of the mountain range. Consequently, the leeward plain did not have a strong surface wind.

When $F_{m}$ was in the range 0.63-1.04 (the Convexity-noSHF-F0.63, Convexity-noSHF-F0.83, and Convexity-noSHF-F1.04 cases), the hydraulic jump appeared only above the straight ridge section (cross Section A3). This result was similar to the result of the Convexity-noSHF case, with an $F r_{m}$ of 0.42 described in Section 3 (Figs. 4, 5). In other words, a jump did not occur above the semi-basin (cross Section A1). Consequently, a strong wind appeared only in the leeward plain of the semi-basin. These results supported our basic conclusion about downslope windstormsthat downslope winds easily reach the leeward plain of the semi-basin.

When the $F r_{m}$ exceeded 1.25 (the ConvexitynoSHF-F1.25, the Convexity-noSHF-F1.48, and the Convexity-noSHF-F1.63 cases), no hydraulic jump appeared above the leeward slope. But, unlike the low- $F r_{m}$ case, a strong surface wind occurred along the entire leeward plain, as if the effect of the convex part of the terrain had disappeared.

\subsection{Impact of convexity shape}

The surface wind speed should depend on the amplitude $\left(A_{b}\right)$ and wavelength $\left(L_{b}\right)$ of the convexity. To understand the nature of this dependence, we examined the results of sensitivity experiments using the 36 combinations of $A_{b}$ and $L_{b}$. These combinations included the convexity parameters for the Karakkaze region and the Tokachi-Kaze region. The configurations of these experiments were the same as those in the Convexity-noSHF case with an $F r_{m}$ of 0.42 in Section 3 (Table 4).

When the aspect ratio of the convexity $\left(A_{b} / L_{b}\right)$ exceeded $\sim 0.5$ (Table 4 ), the strong-wind region (wind speeds $>8 \mathrm{~m} \mathrm{~s}^{-1}$ ) appeared in a manner similar to the way it appeared in the Convexity-noSHF case (see Figs. 3,4 ). In contrast, when $A_{b}$ was smaller and $L_{b}$ was larger, the flow pattern was similar to the pattern along cross Section A3 (Fig. 5); that is, a strong-wind region did not appear. Thus, it was concluded that the convex mountain range around the Kanto Plain had a topography that was favorable for the Karakkaze.

\section{Results of the Convexity-SHF case}

According to Kusaka et al. (2011), the Karakkaze's wind speed varies diurnally, strong during the day and weak at night. They have also shown that the mixed layer during the day transfers a large amount of momentum from the free atmosphere above the planetary boundary layer to the surface. The diurnal behavior of the wind speed indicates that SHFs affect the wind. Here, we investigate the effect of SHFs on the winds from the convex area.

As was the case with the Convexity-noSHF case, the strong-wind region appeared in the leeward plain of the semi-basin during the day in the Convexity-SHF case; however, in the Convexity-SHF case, that region was larger (Fig. 6a). In the Convexity-SHF case, the area of wind divergence in the leeward plain of the semi-basin was also larger (Figs. $6 \mathrm{~b}-\mathrm{d}, \mathrm{X}=345-400$ $\mathrm{km}$ ). These results suggest that the strong-wind region had expanded because the SHFs produced vertical and horizontal diffusion in the mixed layer. In contrast, the speed of the surface wind was lower in the ConvexitySHF case than in the Convexity-noSHF case. Two processes accounted for the weakening of the surface wind speed. One process was the transfer of the momentum of the wind in the strong-wind region to the surrounding region via the vertical and horizontal diffusion in the mixed layer. The second process was the development of a westward component of the pressure-gradient force between the mountain and plain due to the difference of the air temperatures at the mountain slope and above the plain.

The contour lines of wind speed near $16 \mathrm{~m} \mathrm{~s}^{-1}$ along the $\mathrm{A} 1$ cross section descended from 1.5 to $0.5 \mathrm{~km}$ for $X$ in the range $370-420 \mathrm{~km}$ (Fig. 7a). This pattern was similar to the pattern of the contour lines for wind speeds near $22 \mathrm{~m} \mathrm{~s}^{-1}$ in the Convexity-noSHF case (Fig. 4a). At the same time, a strong downdraft appeared in the leeward plain of the semi-basin at X-positions in the approximate range $390-410 \mathrm{~km}$ (Fig. 7b). These X-positions occurred within the strong-wind region (Fig. 6a). The Y-component of the wind in the $\mathrm{Y}-\mathrm{Z}$ cross Section A2 was similar to its counterpart in the Convexity-noSHF case, except that the airflows were weaker (Fig. 7c). The values of the vertical wind speed and potential temperature in this Y-Z cross section (Fig. 7d) were also similar to their values in the Convexity-noSHF case (Fig. 4d). The $\mathrm{X}-\mathrm{Z}$ cross sections of wind speed and potential temperature $(\theta)$ along A3 (Fig. 8) indicated the occurrence 
(a) Windspeed at $Z=10 \mathrm{~m}$

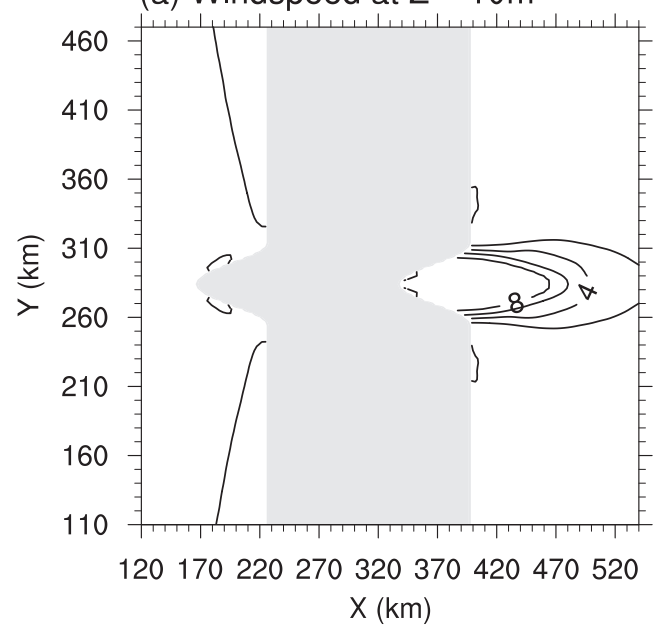

(c) Wind divergence at $Z=10 \mathrm{~m}$

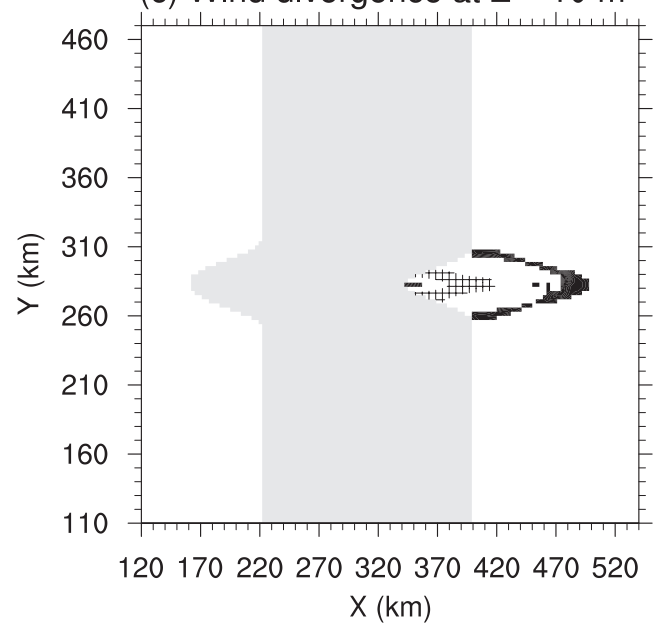

(b) Wind at $Z=10 \mathrm{~m}$

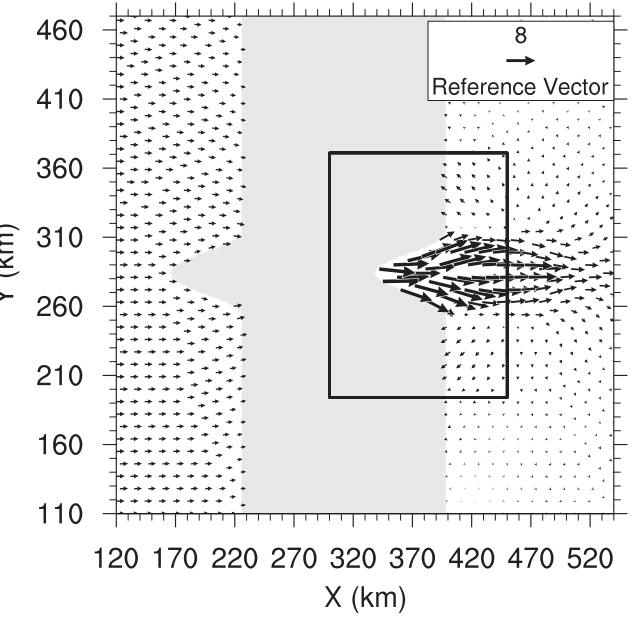

(d) Enlarged view of (b)

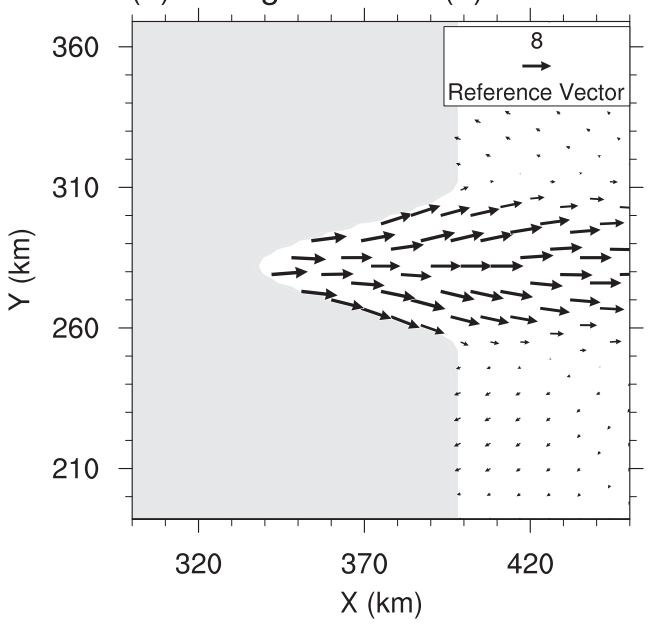

Fig. 6. Same as Fig. 3 except for from the Convexity-SHF case at 6FT.

of a hydraulic jump identical to the jump that occurred in the Convexity-noSHF case (Fig. 5). These results imply that the structure of the strong-wind region (i.e., absence of a hydraulic jump at A1, presence of a hydraulic jump at A3, and strong surface winds in the lee of the semi-basin) did not depend strongly on SHFs.

However, the diurnal variations of surface wind speed and potential temperature depended strongly on the SHFs. In the Convexity-SHF case, the surface wind speed at P1 was strong between 3 and 8 FT and was weak after 12 FT (Fig. 9a). The surface wind speed and potential temperature both underwent diurnal variations (Fig. 10a). The potential temperature started to increase after sunrise (0.38 FT, 0623 LST) and decreased after sunset (11.4 FT, 1724 LST). This pattern was consistent with the pattern observed in a previous study (Kusaka et al. 2011). These results suggest that the surface flows gained momentum from the upper air due to the development of the mixed layer but were decoupled from the upper air during the night because of the development during the night of a stable surface layer in the plain area.

In contrast, the surface wind speed and potential temperature did not undergo diurnal variations in the Convexity-noSHF case (Figs. 9b, 10b). Wind speed and temperature started to increase from $3 \mathrm{FT}$, and both were almost constant from 12 FT. These results showed that the stable surface layer did not occur during the night because the downward sensible heat flux and radiative cooling were neglected in the Convexity-noSHF case. The reason that the temperature rose from 3 FT to 12 FT was the descent of upper air 
(a) Windspeed

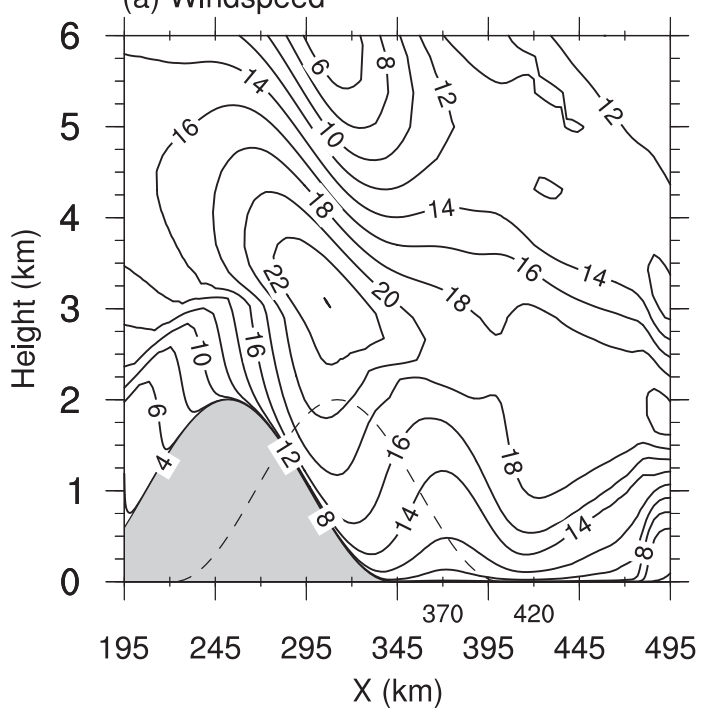

(c) $\mathrm{V}$

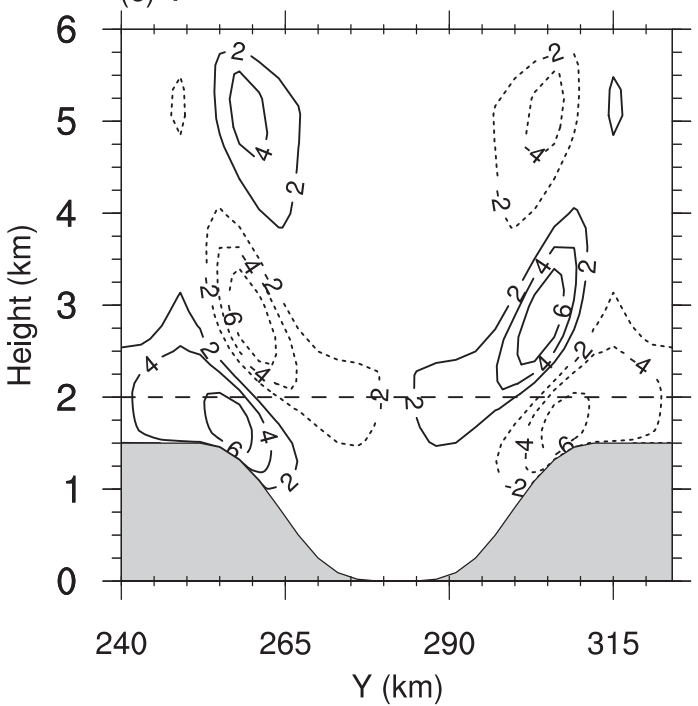

(b) W and $\theta$

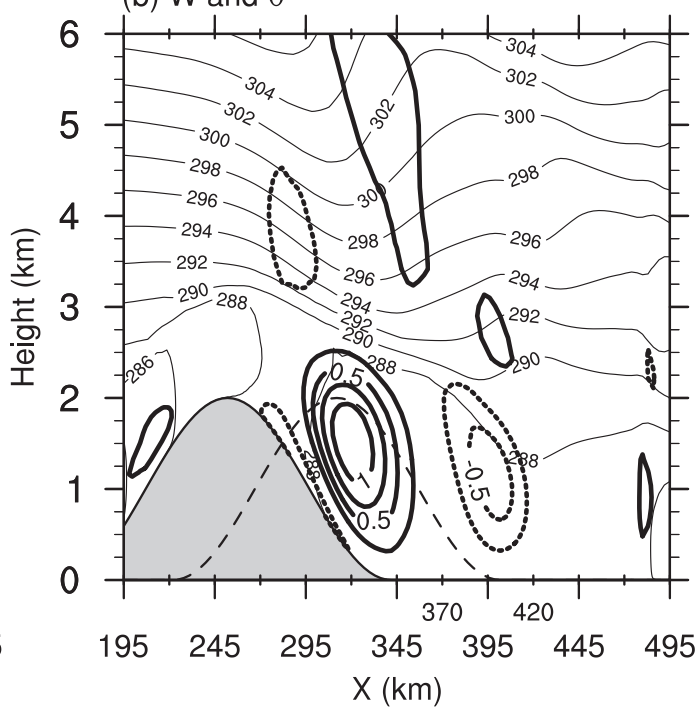

(d) W and $\theta$

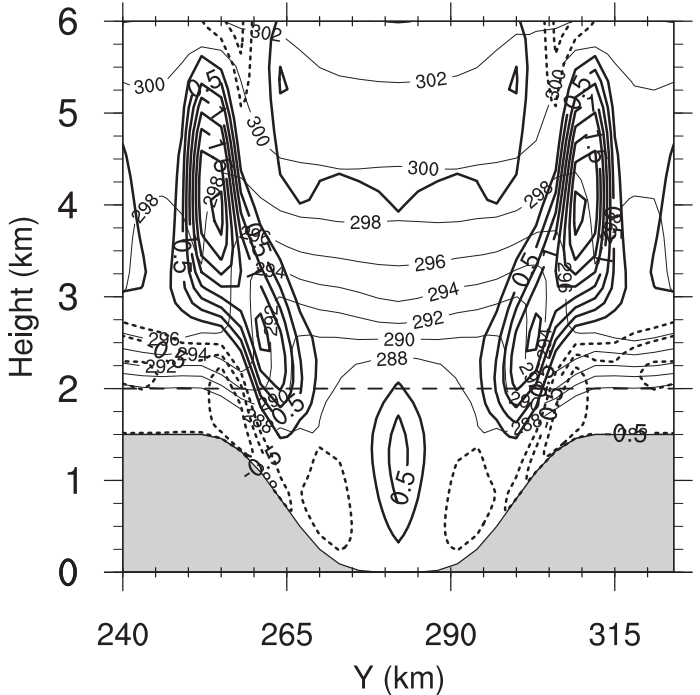

Fig. 7. Same as Fig. 4 except for from the Convexity-SHF case at 6FT.

with a high potential temperature.

When $A_{b}$ and $L_{b}$ both equaled $60 \mathrm{~km}$, the impact of the $F r_{m}$ on the locally strong-wind region was the same in the Convexity-SHF and Convexity-noSHF cases (Table 5). This result suggests that the basic conditions for the Karakkaze wind did not change, even if a mixed layer developed during the daytime.

In contrast, the impact of the convexity shape differed between the Convexity-noSHF and ConvexitySHF cases (Table 6). In the Convexity-SHF cases, a strong wind occurred in the leeward plain of the semibasin when the aspect ratio of convexity $\left(A_{b} / L_{b}\right)$ exceeded $\sim 0.3$ (Table 6), which is smaller than the critical ratio of about 0.5 in the Convexity-noSHF case (Table 4). Therefore, the critical aspect ratio of the experiment was larger in the Convexity-noSHF than in the Convexity-SHF cases. These results suggest that a developing mixed layer can change the critical $F r_{m}$ for a hydraulic jump over a convex region.

To clearly show the impact of convexity scales on strong winds, future studies should focus on the impact of convexity scales under various atmospheric conditions, regardless of the presence of SHFs. 
(a) Windspeed

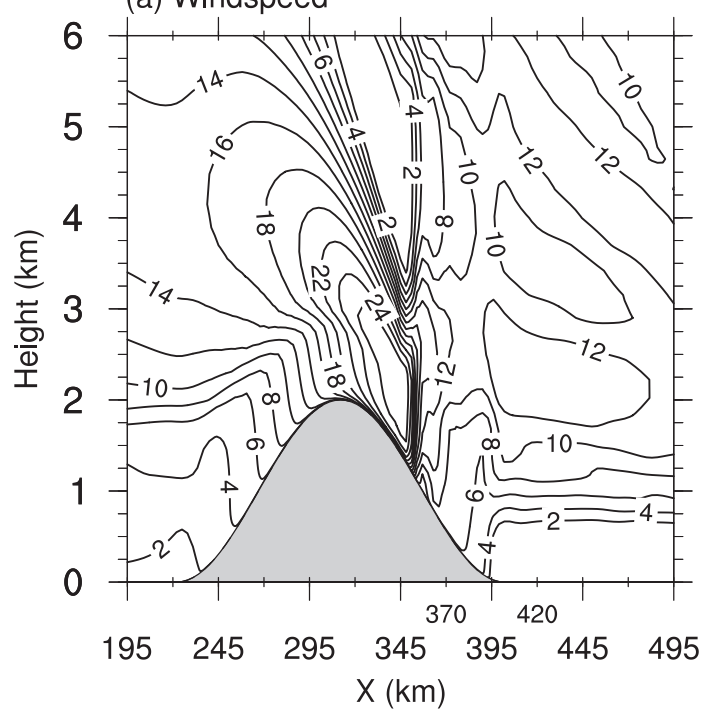

(b) $\theta$

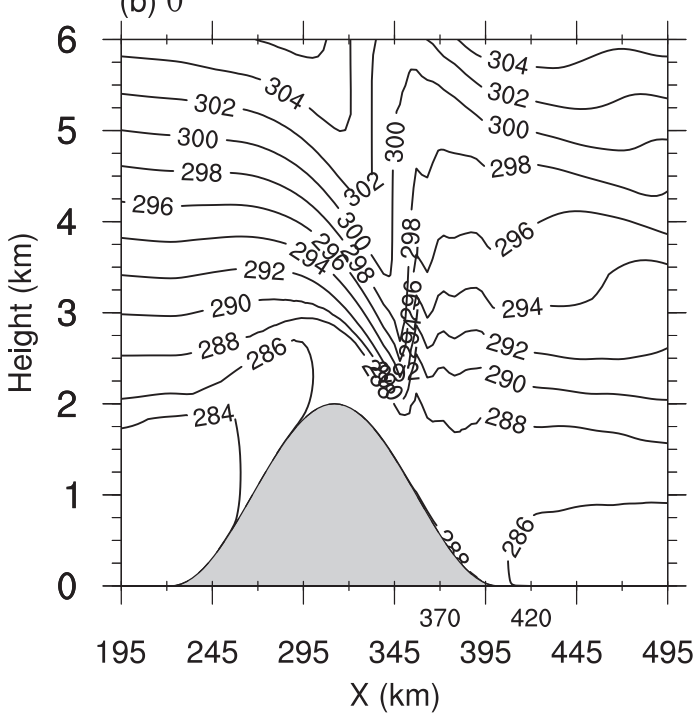

Fig. 8. Same as Fig. 5 except for from the Convexity-SHF case at 6FT.

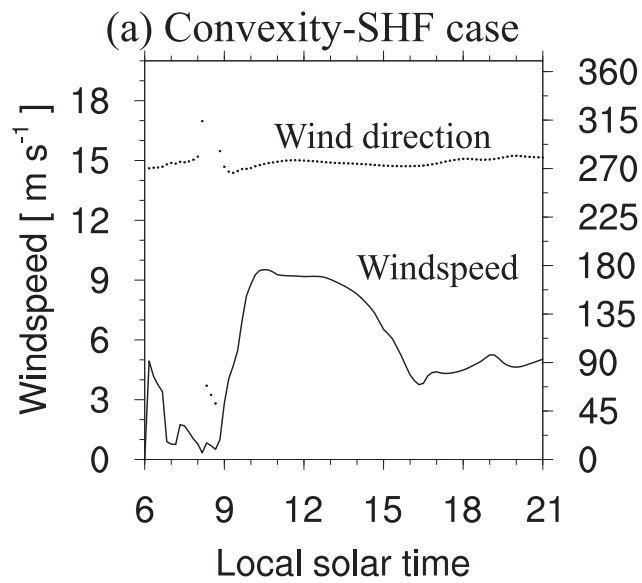

(b) Convexity-noSHF case

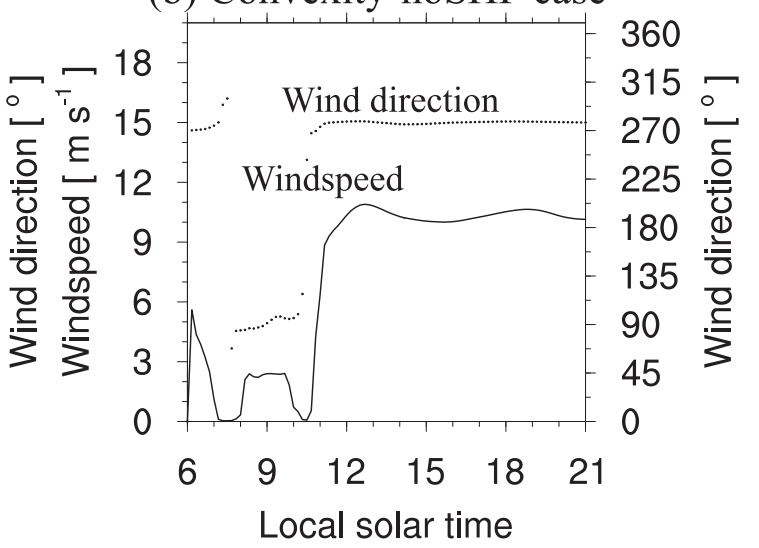

Fig. 9. Diurnal variation of wind at P1 in Fig. 2a at $10 \mathrm{~m}$ height in (a) the Convexity-SHF case and (b) the Convexity-noSHF case. The dots and lines are wind direction and wind speed, respectively.

\section{Discussion}

\subsection{Comparison with the Straight-SHF case}

To determine how the Straight-SHF case (straightridge case) led to a different downslope windstorm than the Convexity-SHF case, the flow pattern of only the Straight-SHF case was examined because the essential structure of the strong-wind region in the case with the straight mountain range should not strongly depend on SHFs, as we found for the Convexity and Convexity-SHF cases. In Fig. 11a, the lee slopes of the mountain range corresponding to $\mathrm{X}=320-345$ $\mathrm{km}$ were associated with wind speeds exceeding 16 $\mathrm{m} \mathrm{s}^{-1}$. Further downwind from $\mathrm{X}=345 \mathrm{~km}$, in the leeward plain area, this strong-wind region separated from the ground and reached more than $2 \mathrm{~km}$ in height before leveling off. On the ground, the wind speed was less than $2.0 \mathrm{~m} \mathrm{~s}^{-1}$ in the plain area leeward of the mountain range. In addition, the potential temperatures along the cross section revealed isentropic lines corresponding to temperatures $\geq 288 \mathrm{~K}$ that rapidly ascended (Fig. 11b). The implication is that strong 

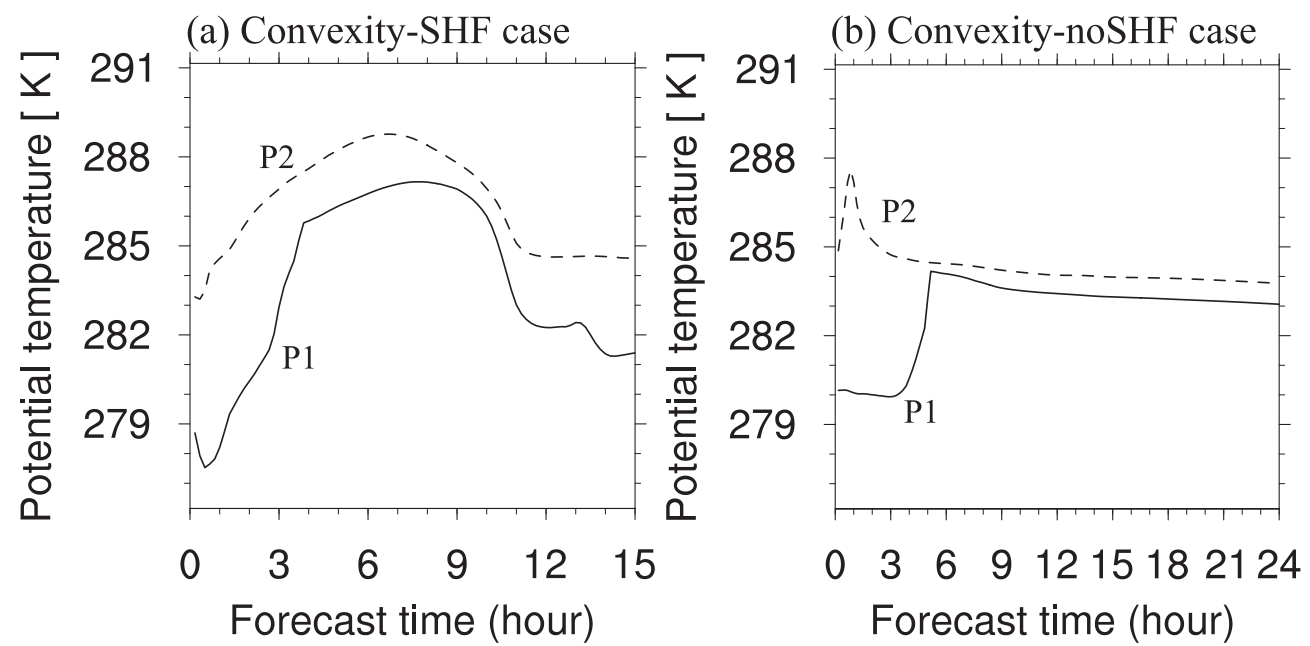

Fig. 10. Diurnal variation of potential temperature at P1 and P2 in Fig. 2a at $2 \mathrm{~m}$ height in (a) the Convexity-SHF case and (b) the Convexity-noSHF case.

(a) Windspeed

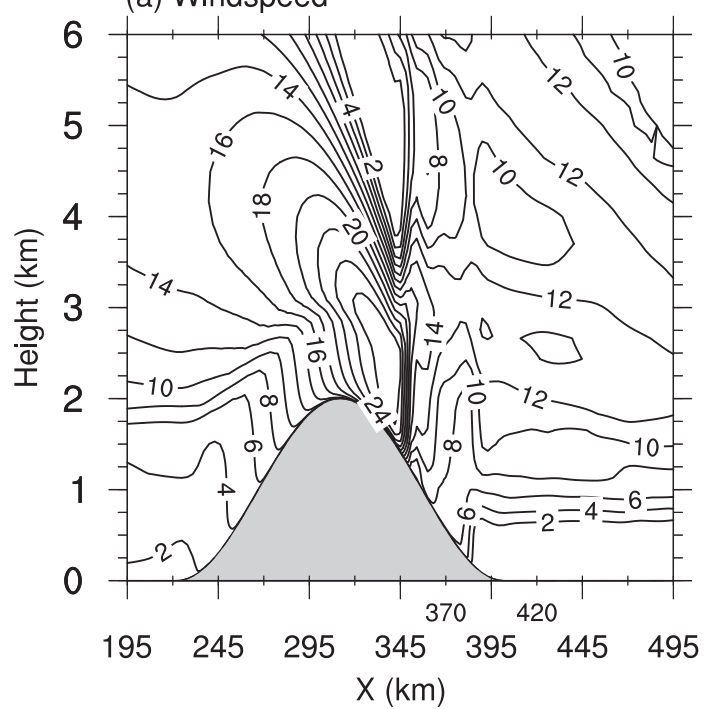

(b) $\theta$

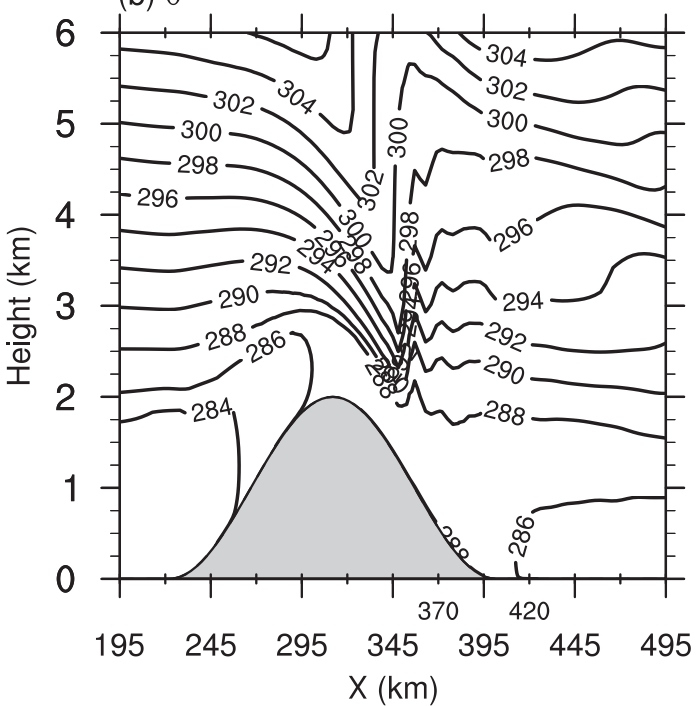

Fig. 11. Same as Fig. 5 except for the result in the cross section B1 (see Fig. 2b) in the Straight-SHF case at 6FT.

updrafts appeared near the ascending isentropic lines. The features of the wind and potential temperatures thus showed that a hydraulic jump occurred in the lee slopes of the mountain range. Because of this hydraulic jump, weak winds appeared near the surface in the lee region of the mountain range. The strong-wind region, therefore, did not appear in the lee area of the mountain in the Straight-SHF case. These results clearly showed that the appearance of the Karakkaze was due to the convex section of the mountain range.

\subsection{Effect of a saddle in the mountain range (Convexity-Saddle-SHF case)}

A gap, or saddle, in a mountain range can produce strong winds called "gap winds" (e.g., Scorer 1952; Overland 1984; Dorman et al. 1995; Seibert 1990; Flamant 2002; Zängl 2003; Mayr et al. 2004; Mass et al. 2014). The effects of a saddle on the local winds in Japan have also been investigated (e.g., Arakawa 1969; Saito 1993; Sasaki et al. 2010). For example, Saito (1993) has shown that the local strong wind 
(a) Topography

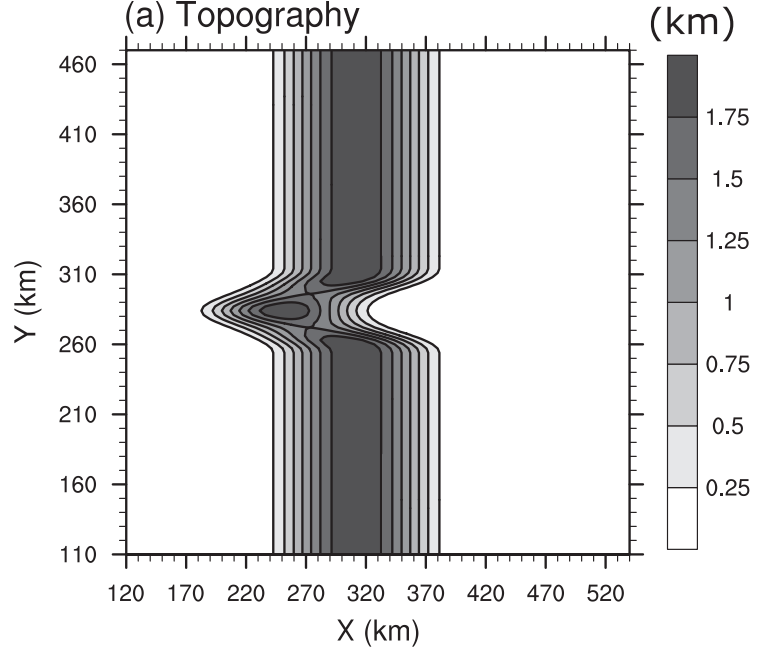

(b) Windspeed at $Z=10 \mathrm{~m}$

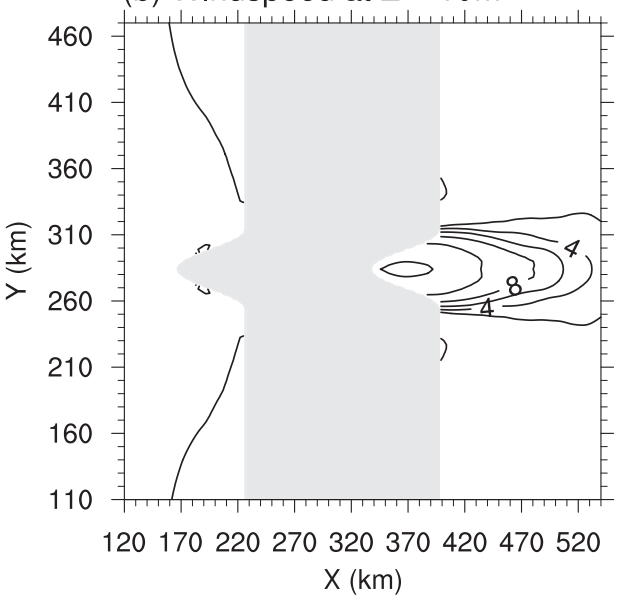

Fig. 12. Horizontal cross section of the Convexity-Saddle-SHF case at 6 FT. (a) Topography for the ConvexitySaddle-SHF case. The contour intervals are $0.25 \mathrm{~km}$. (b) Same as Fig. 3a except for the result of the ConvexitySaddle-SHF case.

"Yamaji-Kaze" can easily extend leeward of the saddle of a mountain range.

The results of the present study indicate that local winds (e.g., a Karakkaze) can blow in the leeward plain of the semi-basin near a mountain range, even if the range has no saddles. To confirm the effects of the saddle on the Karakkaze, we ran an additional numerical experiment with a mountain range that had both a convex feature and two saddles (Fig. 12a). These two saddles were located $12 \mathrm{~km}$ north and south of the centerline of the convex part of the range ( $Y=273$ and $297 \mathrm{~km}$, respectively). The depth and width of each saddle were 0.5 and $24 \mathrm{~km}$, respectively, and thus approximated the Usui saddle in the Kanto mountains (the triangle in Fig. 1a) and the Mikuni saddles in the Mikuni mountains (the square in Fig. 1a). Only the case with surface heat fluxes was analyzed because the essential structure of the strong-wind region in the case should not depend strongly on SHFs. Hereafter, this experiment is called the "Convexity-Saddle-SHF case", and it was compared to the Convexity-SHF case.

The horizontal distributions of wind speed at a height of $10 \mathrm{~m}$ were very similar in the ConvexitySaddle-SHF case and the Convexity-SHF case (Fig. $12 \mathrm{~b})$. However, the maximum wind speed was slightly stronger in the Convexity-Saddle-SHF case (11.0 $\left.\mathrm{m} \mathrm{s}^{-1}\right)$ than in the Convexity-SHF case $\left(9.3 \mathrm{~m} \mathrm{~s}^{-1}\right)$ because the air tended to flow over the mountain at the saddles; therefore, while mountain saddles are not essential for the formation of the Karakkaze, they can increase the strength of a Karakkaze.

We did not estimate the effects of the saddles in a realistic terrain case (e.g., the Usui and Mikuni saddles) in this study. To examine such effects, future studies should involve numerical simulations with more realistic terrains.

\section{Conclusions}

In the present study, we examined a possible mechanism of formation of the local strong wind called "Karakkaze" that occurs in the Kanto Plain in Japan. The numerical simulations were run with the WRF model using an idealized mountain range with and without a convex feature. The study focused on the effects of the convexity on the formation of the Karakkaze.

The results, which revealed that the strong-wind region appeared in the semi-basin and the leeward plain of the semi-basin, agreed with observations. Furthermore, in agreement with observations, the simulation reproduced the area of lower wind speeds adjacent to the strong-wind region. In contrast, a strong-wind region did not form in the leeward plain area in the case of a mountain range lacking convexity. A comparison of these results showed that the convex feature played an important role in the formation of the Karakkaze.

Sensitivity experiments showed that locally strong winds appeared in the semi-basin and the leeward 
plain of the semi-basin when the $F r_{m}$ was in the range $0.42-1.04$. We thus concluded that the convex feature made it easier for the downslope windstorms to reach the leeward plain.

Another sensitivity experiment showed that strong winds appeared in the semi-basin and the leeward plain of the semi-basin only when the aspect ratio of convexity $\left(A_{b} / L_{b}\right)$ exceeded $\sim 0.5$. This result was consistent with the effect of the convex feature in the Kanto mountain range. Therefore, it was concluded that the shape of the convex feature in the Kanto range favored the formation of a locally strong Karakkaze.

The basic structure of the strong-wind region did not depend strongly on SHFs when the strongest winds blew in the leeward plain. However, the surface wind speed decreased in the semi-basin and in the lee of the semi-basin when SHFs were added. Moreover, because of the development of the mixed layer, the strong-wind region was larger in the Convexity-SHF case than in the Convexity-noSHF case.

When the amplitude and wavelength of the convexity were similar to those in the Karakkaze region, the impact of the $F r_{m}$ on the locally strong-wind region was similar for both the Convexity-noSHF and Convexity-SHF cases. However, the critical aspect ratio for the formation of a locally strong wind in the leeward plain of the semi-basin increased because of the development of a mixed layer in the ConvexitySHF case. A further sensitivity experiment with terrain shape suggested that while the saddles of the mountain range were not essential to the formation of the Karakkaze, they could increase the strength of the Karakkaze.

The present study did not estimate the effects of the saddles in a realistic terrain case (e.g., the Usui and Mikuni saddles). To examine such effects, future studies should involve numerical simulations with more realistic terrain. Moreover, further studies of the three-dimensional analytical solution of mountain waves would be required to clearly show the linear effects of convexity on strong winds.

\section{Supplements}

Supplement 1 shows the effect of the Coriolis force on the Karakkaze.

\section{Acknowledgments}

This work was supported by the Cabinet Office, Government of Japan, Cross-ministerial Strategic Innovation Promotion Program (SIP), "Technologies for creating next-generation agriculture, forestry and fisheries" (funding agency: Bio-oriented Technology
Research Advancement Institution, NARO). We used the Generic Mapping Tool and NCAR Command Language to draw figures in this study.

\section{References}

Arakawa, S., 1969: Climatological and dynamical studies on the local strong winds, mainly in Hokkaido, Japan. Geophys. Mag., 34, 359-425.

Brinkmann, W. A. R., 1971: What is a foehn? Weather, 26, 230-240.

Chen, F., and J. Dudhia, 2001: Coupling an advanced land surface-hydrology model with the Penn State-NCAR MM5 modeling system. Part I: Model description and implementation. Mon. Wea. Rev., 129, 569-585.

Cook, A. W., and A. G. Topil, 1952: Some examples of chinooks east of the mountains in Colorado. Bull. Amer. Meteor. Soc., 33, 42-47.

Dorman, C. E., R. C. Beardsley, and R. Limeburner, 1995: Winds in the Strait of Gibraltar. Quart. J. Roy. Meteor. Soc., 121, 1903-1921.

Dudhia, J., 1989: Numerical study of convection observed during the winter monsoon experiment using a mesoscale two-dimensional model. J. Atmos. Sci., 46, 3077-3107.

Elvidge, A. D., and I. A. Renfrew, 2016: The causes of foehn warming in the lee of mountains. Bull. Amer. Meteor. Soc., 97, 455-466.

Epifanio, C. C., and D. R. Durran, 2001: Three-dimensional effects in high-drag-state flows over long ridges. $J$. Atmos. Sci., 58, 1051-1065.

Flamant, C., P. Dobrinski, L. Nance, R. Banta, L. Darby, J. Dusek, M. Hardesty, J. Pelon, and E. Richard, 2002: Gap flow in an Alpine valley during a shallow south föhn event: Observations, numerical simulations, and hydraulic analogue. Quart. J. Roy. Meteor. Soc., 128, 1173-1210.

Fudeyasu, H., T. Kuwagata, Y. Ohashi, S. Suzuki, Y. Kiyohara, and Y. Hozumi, 2008: Numerical study of the local downslope wind "Hirodo-kaze" in Japan. Mon. Wea. Rev., 136, 27-40.

Gaberšek, S., and D. Durran, 2004: Gap flows through idealized topography. Part I: Forcing by large-scale winds in the nonrotating limit. J. Atmos. Sci., 61, 28462862.

Gohm, A., G. J. Mayr, A. Fix, and A. Giez, 2008: On the onset of bora and the formation of rotors and jumps near a mountain gap. Quart. J. Roy. Meteor. Soc., 134, 21-46.

Grisogono, B., and D. Belušić, 2009: A review of recent advances in understanding the meso and microscale properties of the severe Bora wind. Tellus A, 61, 1-16.

Jaubert, G., and J. Stein, 2003: Multiscale and unsteady aspects of a deep föhn event during MAP. Quart. J. Roy. Meteor. Soc., 129, 755-776.

King, J. C., A. Kirchgaessner, S. Bevan, A. D. Elvidge, P. 
Kuipers Munneke, A. Luckman, A. Orr, I. A. Renfrew, and M. R. van den Broeke, 2017: The impact of föhn winds on surface energy balance during the 20102011 melt season over Larsen C Ice Shelf, Antarctica. J. Geophys. Res., 122, 12062-12076.

Klemp, J. B., and D. R. Durran, 1987: Numerical modeling of Bora winds. Meteorol. Atmos. Phys., 36, 215-227.

Klemp, J. B., and D. K. Lilly, 1987: Numerical simulation of hydrostatic mountain waves. J. Atmos. Sci., 35, 78107.

Kusaka, H., and H. Fudeyasu, 2017: Review of downslope windstorms in Japan. Wind Struct., 24, 637-656.

Kusaka, H., Y. Miya, and R. Ikeda, 2011: Effect of solar radiation amount and synoptic-scale wind on the local wind "Karakkaze" over the Kanto Plain in Japan. $J$. Meteor. Soc. Japan, 88, 327-340.

Lilly, D. K., and J. B. Klemp, 1979: The effects of terrain shape on non-linear hydrostatic mountains waves. $J$. Fluid Mech., 95, 241-261.

Lin, Y.-L., and T.-A. Wang, 1996: Flow regimes and transient dynamics of two-dimensional stratified flow over an isolated mountain ridge. J. Atmos. Sci., 53, 139-158.

Mass, C., M. D. Warner, and R. Steed, 2014: Strong westerly wind events in the strait of Juan de Fuca. Wea. Forecasting, 29, 445-465.

Mayr, G. J., L. Armi, S. Arnold, R. M. Banta, L. S. Darby, D. D. Durran, C. Flamant, S. Gaberšek, A. Gohm, R. Mayr, S. Mobbs, L. B. Nance, I. Vergeiner, J. Vergeiner, and C. D. Whiteman, 2004: Gap flow measurements during the Mesoscale Alpine Programme. Meteorol. Atmos. Phys., 86, 99-119.

Mellor, G. L., and T. Yamada, 1982: Development of a turbulence closure model for geophysical fluid problems. Rev. Geophys. Space Phys., 20, 851-875.

Miller, P. P., and D. R. Durran, 1991: On the sensitivity of downslope windstorms to the asymmetry of the mountain profile. J. Atmos. Sci., 48, 1457-1473.

Miltenberger, A. K., S. Reynolds, and M. Sprenger, 2016: Revisiting the latent heating contribution to foehn warming: Lagrangian analysis of two foehn events over the Swiss Alps. Quart. J. Roy. Meteor. Soc., 142, 2194-2204.

Mlawer, E. J., S. J. Taubman, P. D. Brown, M. J. Iacono, and S. A. Clough, 1997: Radiative transfer for inhomogeneous atmospheres: RRTM, a validated correlated-k model for the longwave. J. Geophys. Res., 102, 1666316682.

Nakanishi, M., and H. Niino, 2009: Development of an improved turbulence closure model for the atmospheric boundary layer. J. Meteor. Soc. Japan, 87, 895-912.

Nishi, A., and H. Kusaka, 2019: Comparison of spatial pattern and mechanism between convexity and gap winds. SOLA, 15, 12-16.

Oard, J. M., 1993: A method for predicting Chinook winds east of the Montana Rockies. Wea. Forecasting, 8,
166-180.

Overland, J. E., 1984: Scale analysis of marine winds in straits and along mountainous coasts. Mon. Wea. Rev., 112, 2530-2534.

Pitts, R. O., and T. J. Lyons, 1989: Airflow over a twodimensional escarpment. I: Observations. Quart. J. Roy. Meteor. Soc., 115, 965-981.

Raymond, J. D., 1972: Calculation of airflow over an arbitrary ridge including diabatic heating and cooling. $J$. Atmos. Sci., 29, 837-843.

Saito, K., 1992: Shallow water flow having a lee hydraulic jump over a mountain range in a channel of variable width. J. Meteor. Soc. Japan, 70, 775-782.

Saito, K., 1993: A numerical study of the local downslope wind "Yamaji-kaze" in Japan. Part2: Non-linear aspect of the 3-D flow over a mountain range with a col. $J$. Meteor. Soc. Japan, 71, 247-272.

Saito, K., and M. Ikawa, 1991: A numerical study of the local downslope wind "Yamaji-kaze" in Japan. $J$. Meteor. Soc. Japan, 69, 31-56.

Sasaki, K., M. Sawada, S. Ishii, H. Kanno, K. Mizutani, T. Aoki, T. Itabe, D. Matsushima, W. Sha, A. T. Noda, M. Ujiie, Y. Matsuura, and T. Iwasaki, 2010: The temporal evolution and spatial structure of the local easterly wind "Kiyokawa-dashi" in Japan. Part II: Numerical simulations. J. Meteor. Soc. Japan, 88, 161-181.

Scorer, R. S., 1952: Mountain-gap winds; A study of surface wind at Gibraltar. Quart. J. Roy. Meteor. Soc., 78, 5361.

Seibert, P., 1990: South föhn studies since the ALPEX experiment. Meteorol. Atmos. Phys., 43, 91-103.

Skamarock, W. C., J. B. Klemp, J. Dudhia, D. O. Gill, D. M. Barker, M. G. Duda, X.-Y. Huang, W. Wang, and J. G. Powers, 2008: A description of the Advanced Research WRF Version 3. NCAR Technical Note, NCAR/TN-475+STR, $126 \mathrm{pp}$.

Smith, R. B., 1985: On severe downslope winds. J. Atmos. Sci., 42, 2597-2603.

Smith, R. B., 1987: Aerial observations of the Yugoslavian Bora. J. Atmos. Sci., 44, 269-297.

Sprenger, M., and C. Schär, 2001: Rotational aspects of stratified gap flows and shallow föhn. Quart. J. Roy. Meteor. Soc., 127, 161-187.

Whiteman, C. D., 2000: Mountain Meteorology: Fundamentals and Applications. Oxford University Press, 376 pp.

Yoshino, M. M., 1986: Climate in a Small Area. New Edition. Chijin Shokan, 298 pp (in Japanese).

Zängl, G., 2003: Deep and shallow south foehn in the region of Innsbruck: Typical features and semi-idealized numerical simulation. Meteorol. Atmos. Phys., 83, 237-261.

Zängl, G., B. Chimani, and C. Häberli, 2004: Numerical simulations of the foehn in the Rhine Valley on 24 October 1999 (MAP IOP 10). Mon. Wea. Rev., 132, 368-389. 